\title{
Conjugalidade e a União de Duas Histórias de Vida: Uma Discussão Ilustrada a Partir do Filme "A História de Nós Dois"
}

\author{
Débora Silva de Oliveira* \\ Fundação Escola Superior do Ministério Público, Porto Alegre, Brasil \\ Complexo de Ensino Superior de Cachoeirinha, Porto Alegre, Brasil
}

\begin{abstract}
RESUMO
$\mathrm{O}$ artigo discute a conjugalidade através de conceitos da terapia de casal, ilustrados com passagens do filme A História de Nós Dois. Primeiramente, apresentamos uma síntese do filme e em seguida discutimos os seguintes eixos temáticos: contrato metafórico; mudanças emocionais; individualidade versus conjugalidade; concepção de casamento; expressão de afetos; percepção idealizada do relacionamento; família de origem; coesão e complementaridade. Apontamos que a conjugalidade contempla a inclusão de dois desejos, duas histórias de vida, que se aperfeiçoam em um jogo contínuo. A conjugalidade pode também se transformar em fonte de crescimento e desenvolvimento pessoal, se houver espaço para trocas e diferenças pessoais. A discussão colabora para a reflexão de profissionais que trabalham, direta ou indiretamente, com casais.
\end{abstract}

Palavras-chave: conjugalidade; individualidade; terapia de casal.

\begin{abstract}
Conjugality and the Union of Two Life stories:

A Discussion Illustrated with the Movie "The Story of Us"

The article discusses conjugality through couples therapy concepts, illustrated with episodes of the movie The Story of Us. At first, a summary of the movie is presented and, subsequently, the following topics are discussed: metaphoric contract; emotional changes; individuality versus conjugality; marriage conception; expression of feelings; idealized relationship perception; family of origin; cohesion and complementarity. We highlight that conjugality implicates the inclusion of two continuously improving desires and life stories. Conjugality can also become a source of personal growth and development when it allows exchanges and personal differences between the couple. The discussion contributes to a reflection among professionals who work directly or indirectly with couples.
\end{abstract}

Keywords: conjugality; individuality; couples therapy.

A instituição casamento e os modelos conjugais sofreram constantes modificações e mudanças de paradigma. Os questionamentos dos méritos e da validade do casamento passaram a ser realizados na medida em que novos contratos puseram fim aos paradigmas tradicionais. O que antes era entendido como "até que a morte nos separe", na contemporaneidade passa a ser entendido como "que seja infinito enquanto dure". Assim, o mito do casamento e a utopia do amor ro- mântico "para sempre e único" passaram a ser questionados (Mosmann, Wagner \& Féres-Carneiro, 2006).

Dentre as diferentes formas de relação, a relação conjugal parece ser a que mais exige das pessoas, uma vez que contempla duas histórias de vida, originárias de famílias distintas, que convivem juntas e trocam experiências (Valle \& Osório, 2004). Na visão clássica, o casamento era constituído a partir de uma construção conjunta da realidade de duas pessoas

\footnotetext{
Endereço para correspondência: Débora Silva de Oliveira - debora_deoli@yahoo.com.br.
} 
(Norgren, Souza, Kaslow, Hammerschmidt \& Sharlin, 2004), e era caracterizado por uma vinculação, frequente, intensiva e estável (Willi, 1975). Os paradigmas relacionais eram associados aos modelos tradicionais, hierarquizados e patriarcalistas, e estabelecidos através de um contrato social entre as famílias. O poder e a autoridade centralizavam-se na figura do homem, autoridade máxima da relação conjugal (Áries, 1981).

Já na contemporaneidade, os cônjuges se deparam com diferenças e ideais distintos ao longo do ciclo de vida do casamento. Em contraposição aos ideais do passado que valorizavam a dependência entre os cônjuges, denotando uma ideia de "encaixe" (Valle \& Osório, 2004), os ideais contemporâneos de relação conjugal preconizam a autonomia e a satisfação de cada cônjuge (Féres-Carneiro, 1998).

No paradigma sistêmico, casamento e conjugalidade podem ser entendidos de diferentes formas, mas sua conceituação se sobrepõe uma à outra. Na definição de Singly (1988), casamento implica a construção de uma nova identidade para os cônjuges, de um "euconjugal", que se constrói a partir das interações. Para Whitaker (1995), um dos pioneiros da terapia familiar e de casal, casamento consistiria em um modelo adulto de intimidade, que contempla uniões e separações entre dois indivíduos, em que um indivíduo completaria o outro, na medida em que busca neste o que sente falta em si mesmo. Já para Willi (1995), o casamento se caracterizaria como diferente de todas as outras formas de relações, uma vez que quando duas pessoas decidem viver juntas, tem que se modificar internamente e se reorganizar. McGoldrick (2001) vai além, considera que o casamento deveria ser entendido muito mais do que a união de dois indivíduos, mas a modificação de dois sistemas inteiros e a criação de um terceiro subsistema familiar. Já o termo conjugalidade é definido, por alguns pesquisadores brasileiros, como uma dimensão psicológica compartilhada da vida do casal, com dinâmica inconsciente, com leis e funcionamento específico, associada à criação de uma "identidade conjugal" (Féres-Carneiro, 1998).

Nesse sentido, o presente artigo buscou discutir o tema da conjugalidade e do casamento através de conceitos da terapia de família e de casal, ilustrados por meio de passagens do filme A História de Nós Dois (The Story of Us, EUA, 1999). Pretende-se com esta discussão contribuir para os estudos que abordam o tema conjugalidade, bem como colaborar para a reflexão de profissionais que trabalham, direta ou indiretamente, com casais. Inicialmente, será apresentada uma síntese do filme a fim de contextualizar a discussão e, em seguida, serão discutidos alguns eixos temáticos elencados no presente artigo, que cercam o tema conjugalidade, e que serão ilustrados por trechos do filme. Dentre esses eixos temáticos, destacam-se alguns dos desafios inerentes da relação conjugal, os quais serão examinados a seguir: contrato metafórico; mudanças emocionais da relação; dimensão individualidade versus conjugalidade; concepção de casamento conforme o gênero; expressão de afetos e de sentimentos; percepção idealizada de seu parceiro e de seu relacionamento; a influência da família de origem na relação e, por fim, a coesão e a complementaridade. Cabe destacar que não se pretende, com esse artigo, esgotar cada um desses eixos temáticos, uma vez que existe uma heterogeneidade de questões que envolvem e influenciam a relação de casal, mas de discuti-los a partir da trama do filme.

\section{The Story of Us: 0 filme}

A história de nós dois foi produzido e dirigido em 1999, nos EUA, por Rob Reiner, Jessie Nelson e Alan Zwebel. No elenco, entre outros atores, encontram-se como personagens principais Bruce Willis e Michelle Pfeiffer. Este filme, categorizado como gênero romance, de abordagem leve e sensível aos problemas de um casal comum, discute a relação de Ben (Bruce Willis) e Katie (Michelle Pfeiffer). Ben e Katie estão casados há 15 anos e têm dois filhos Josh (Jake Sandvig), de 12 anos, e Erin (Colleen Rennison) de 10.

Aparentemente, Ben e Katie vivem o casamento de maneira confortável e feliz. Contudo, há mais ou menos três anos que ambos percorrem terapeutas de diferentes abordagens, a fim de buscar na relação aspectos emocionais e individuais, que julgavam ter perdido ao longo do casamento. $\mathrm{O}$ filme transcorre durante o período de férias (três meses) dos filhos, Josh e Erin, que costumavam ir, anualmente, para um acampamento de verão. Nessa época, ambos, Ben e Katie, resolvem separar-se, ainda que Ben ache ridícula a separação, uma vez que sabe que se amam e acredita que todos os casais passam por isso. Separados, cada um tenta recomeçar sua vida. Katie permanece na residência da família, e relaciona-se de modo amigável com o pai de um coleginha de Josh. Enquanto Ben 
procura continuar o seu trabalho de escritor de livros, acomodando-se, primeiramente, em um hotel, e, posteriormente, em uma casa.

Durante esses três meses, cada um, Ben e Katie, aproveita o período para avaliar sobre a vida que tiveram juntos. Ambos refletem sobre o relacionamento, relembram as situações que passaram juntos - algumas tristes, outras engraçadas - e procuram concluir se ainda há algo de sólido na relação que permita uma reaproximação. Ao final desse período de três meses e com o retorno dos filhos, Ben e Katie percebem que construíram uma história juntos e decidem permanecer casados. O casal se dá conta que uma história entre casais não acontece de um dia para a noite e é construída ao longo do tempo.

\section{Conjugalidade: a união de dois sujeitos, de dois desejos, de duas histórias de vida}

Em termos de desenvolvimento, a união de um casal deve ser compreendida como uma fase específica do ciclo de vida da família (Carter \& McGoldrick, 2001). O casamento constitui apenas uma das etapas deste ciclo. De acordo com McGoldrick (2001), o ciclo de vida da família pode ser dividido em seis estágios, a saber: a diferenciação do jovem adulto solteiro de sua família de origem, o novo casal, a presença de filhos pequenos, de filhos adolescentes, de filhos lançando-se para o mundo e o estágio tardio da vida contemplam os demais estágios deste ciclo.

Ao longo do ciclo de vida do casamento, existem inúmeros desafios na convivência da relação a dois, que já se iniciam muito antes deste casamento ser estabelecido. De acordo com Willi (1975), há uma fase anterior denominada formação do casal estável, que é permeada por dúvidas e temores, uma vez que envolve o medo de separar-se da casa de sua família de origem, de entregar-se ao companheiro, do envolvimento em novas obrigações e responsabilidades.

Ao ser estabelecido o casamento, o casal ingressa na fase de estruturação e produção do casamento (Willi, 1975) ou do novo casal (McGoldrick, 2001), que abarca os primeiros anos de vida conjugal e traz como princípio-chave o comprometimento com um novo sistema. Nesse momento, a necessidade de afirmar a identidade do casal e de realinhar os relacionamentos com as famílias de origem e com os amigos para incluir o cônjuge torna-se tarefa primordial para a convivência a dois (McGoldrick, 2001). A convivência, segundo Minuchin e Fischman (1990), exige que os cônjuges busquem conciliar seus diferentes valores, muitas vezes, perdendo na individualidade, porém ganhando no sentimento de pertencimento.

É através da convivência que os casais buscam a satisfação e a qualidade na relação. Cada cônjuge, ao se engajar na relação a dois, experimentaria uma reconstrução de sua identidade conjugal, a qual contemplaria trocas verbais e não verbais que regem suas ações (Féres-Carneiro \& Diniz-Neto, 2010). Esta dinâmica opõe-se à individualidade, a qual consiste na dimensão individual da vida a dois (Magalhães \& Féres-Carneiro, 2003). Conjugalidade, assim, seria a vivência compartilhada da continuidade e da estabilidade do vínculo conjugal (Féres-Carneiro \& Magalhães, 2000).

Dessa forma, o estabelecimento do casal como um sistema supõe um longo processo de adaptação e de acomodação. Minuchin (1990) destaca duas habilidades principais para a implementação da tarefa conjugal: a complementaridade e a acomodação mútua. Cada um dos cônjuges deve apoiar o funcionamento do outro, de modo que ambos possam conceder a sua própria individualidade e a do outro. Para esse autor, a aceitação desta interdependência mútua pode ser prejudicada quando a complementaridade passa a ser confundida com fusão, havendo a expectativa de que o outro preencha suas necessidades e carências. A incapacidade de implementar tal complementaridade pode indicar o empobrecimento da relação conjugal. De acordo com Valle e Osório (2004), esse empobrecimento seria um dos grandes impasses das relações conjugais: quando, não por desamor, mas por limitações inerentes à condição humana, as expectativas iniciais deixam de ser cumpridas, levando a ressentimentos e desapontamentos.

Estudos sobre a relação conjugal têm sido feitos no sentido de examinar a satisfação conjugal e a qualidade dos relacionamentos em casamentos (Norgren et al., 2004; Féres-Carneiro, 1995), bem como de classificar o tipo de relacionamento em ajustados e desajustados (Gottman \& Levenson, 1992), em estáveis e instáveis (Gottman, 1993), casais saudáveis e disfuncionais (Walsh, 2002), dentre outros.

A satisfação conjugal é caracterizada como um fenômeno complexo, consistindo em um conceito subjetivo, que implica ter as necessidades pessoais e desejos satisfeitos (Norgren et al., 2004). Também implica corresponder ao que o outro espera, considerando o dar e o receber recíproco e espontâneo. Está ainda 
relacionada, de acordo com esses autores, a sensações e sentimentos de bem-estar, contentamento, companheirismo, afeição, segurança e a outros fatores que propiciam intimidade no relacionamento. Tal aspecto pode ser elucidado pela fala de Ben, quando, em uma discussão com a esposa, refere que mais do que suas necessidades atendidas gostaria de ter a sensação de segurança através do companheirismo e da afeição: Não estou falando de ser um terceiro filho! Não estou falando de ter minhas necessidades atendidas! Estou falando de um olhar! Algo que diga que estamos no mesmo lado! (Ben). De acordo com Norgren et al. (2004), estes fatores promovem a intimidade no relacionamento e decorrem tanto das expectativas quanto das aspirações dos cônjuges. Quando esses fatores (necessidades pessoais e desejos satisfeitos, sensações e sentimentos de bem-estar, contentamento, companheirismo, afeição e segurança) não estão presentes, a relação pode ser colocada à prova pelo casal. Em uma pesquisa de Gottman e Levenson (1992), que buscou identificar a associação entre processos maritais e dissolução, separação ou divórcio no casamento, foi verificado que a baixa satisfação no casamento esteve diretamente associada a eventuais separações entre os cônjuges.

Um dos desafios presentes na relação conjugal capaz de torná-la satisfatória e saudável é o estabelecimento de regras implícitas e explícitas. Cada casal cria um modelo único em ser casal, que vai se transformando com o passar do tempo (Walsh, 2002). Essa transformação é caracterizada por um contrato metafórico que se estabelece na relação, e se modifica, definindo como cada um é em relação ao outro, seus direitos e deveres. Esse contrato metafórico caracteriza-se por ser implícito, gerando regras próprias, que precisam ser compartilhadas e construídas de forma recíproca, reforçada ou modificada, suscitando níveis de satisfação diferentes para cada um dos cônjuges (Walsh, 2002). A definição dessas regras estaria diretamente relacionada ao grau de sanidade ou disfuncionalidade da relação conjugal (McGoldrick, 2001; Walsh, 2002).

Quando o casal possui dificuldades em perceber que essas mudanças fazem parte do contrato metafórico de uma relação a dois pode caracterizar outro grande desafio do casal da atualidade. Algumas vezes, há a espera que a relação e/ou o cônjuge não mude, tal situação pode dificultar ainda mais o casal lidar com as mudanças emocionais inerentes de uma relação a dois. No filme, o casal se questiona, em tom de cobrança, onde foi parar "a garota do capacete", símbolo de irreverência, de alegria e da união do casal: $O$ que houve com a garota do capacete? (Ben); Acha que não me pergunto isso todo o dia? ... Ben, você ama o que nós éramos. Não pode amar o que nós nos tornamos! (Katie). Nesse caso, percebe-se a dificuldade de Ben identificar as mudanças inerentes do ciclo de vida do casamento, bem como que tais mudanças implicam em acomodações e a estruturação de um novo contrato metafórico da relação a dois com o passar do tempo. De acordo com Whitaker (1995), a relação conjugal pode provocar uma alienação em relação ao passado, é como se os indivíduos ficassem presos aos antigos papéis e imagens de uma relação que não existe mais, tendo dificuldades de assumir novos papéis.

A redução do tempo disponível, as questões econômicas e o destaque profissional de um dos cônjuges também são apontados na literatura como tendo repercussões sobre o casal (Garcia \& Tassara, 2003). A divisão de tarefas diárias e dos cuidados da casa e dos filhos torna-se também uma dificuldade no convívio comum entre os cônjuges, sobretudo em lares em que ambos trabalham (Bernstein, 2002; Zordan, Falcke \& Wagner, 2005). Esse aspecto pode ser elucidado através de um trecho do filme em que o casal retrata a dificuldade de se ouvir em função das grandes demandas do dia a dia quando há filhos pequenos envolvidos: Você não está me ouvindo? Já é difícil com duas crianças, eu não preciso de uma terceira! Eu cuido de tudo por aqui! (Katie); Você é tão crítica! ... Eu não fiz nada certo em 15 anos! (Ben). Ainda nesse sentido, percebe-se que o aumento das expectativas em relação a cada um dos cônjuges e consigo mesmo, e a extrema idealização do outro também podem ser geradores de conflito e tensão na relação conjugal (Zordan et al., 2005).

Os casais contemporâneos são confrontados o tempo todo com forças paradoxais. Se por um lado, há a importância da individualidade, da autonomia e do crescimento e desenvolvimento de cada um, por outro, há a necessidade de criar uma realidade comum do casal, com desejos e projetos comuns (Bernstein, 2000/2002; Féres-Carneiro, 1998). Quanto maior a busca pela autonomia e crescimento, mais o casamento pode se fragilizar. Ao mesmo tempo em que há a maior valorização da conjugalidade pode também haver prejuízo nos projetos individuais (Levandowski, Piccinini \& Lopes, 2009). O equilíbrio entre os espa- 
ços relacionados ao EU e ao TU e também ao NÓS estará associado às vivências de cada etapa do ciclo de vida do casamento e do ciclo vital do próprio desenvolvimento (Falcke, Diehl \& Wagner, 2002). Para esses autores, juntos, os cônjuges precisam negociar o território do "eu" e do "tu", ao mesmo tempo em que estruturam o espaço do "nós". Essa negociação de fronteiras e do estabelecimento da individualidade de cada um, sem que esteja necessariamente relacionada ao outro, torna-se também um dos grandes desafios do casal. No filme, tal aspecto pode ser retratado quando Kate refere que seu cansaço talvez não esteja relacionado ao Ben, mas às inúmeras tarefas do dia a dia: Você não entende que talvez não tenha nada a ver com você! Talvez eu tenha feito 5mil coisas no dia e que eu esteja cansada (Kate); Eu não pedi para você assumir tudo! (Ben). Nesse sentido, percebe-se que são dois indivíduos, com duas formas diversas de pensar e agir, e é no respeito às fronteiras entre estas individualidades que se sustenta a satisfação na vida do casal (McGoldrick, 2001). Somente quando são respeitadas tais fronteiras, a relação pode constituir-se em um espaço de crescimento mútuo e de satisfação pessoal. De acordo com Walsh (2002), os casais saudáveis conseguiriam manter o equilíbrio entre proximidade e distanciamento, comprometendo-se com a relação a dois e com sua continuidade, ao mesmo modo que protegeriam a integridade individual, prevenindo a intrusão externa e a ruptura do vínculo.

No relacionamento conjugal, a busca pelo espaço pessoal e pela individualidade associada à conjugalidade parece gerar expectativas e grandes exigências entre os cônjuges (Zordan et al., 2005). Talvez, em parte, porque todo o fascínio e toda a dificuldade em ser casal se encontra em formar uma dinâmica de duas individualidades em uma conjugalidade, conforme apontou Féres-Carneiro (1998).

O padrão histórico e socialmente definido no que se refere às questões da conjugalidade delimita muitas vezes o que se deve aspirar, alcançar e desejar para uma relação afetivo-sexual entre cônjuges. A aproximação ou o distanciamento desse padrão definiria então outras dificuldades ou problemas na relação conjugal (Garcia \& Tassara, 2003). Nem sempre o que é definido como problema para um ou para outro, é percebido por ambos como tal.

Com a crescente aceitação do divórcio e outras mudanças de paradigmas, a dúvida, sobre se é melhor o casal ficar junto quando o casamento torna-se fonte de angústia e conflitos, apresenta-se cada vez mais nos relacionamentos (Bernstein, 2002). Assim, a concepção de casamento conforme o gênero e a percepção que cada um tem da relação podem interferir na relação conjugal. Para Carter e McGoldrick (2001) se poderia falar de casamento "dele" e casamento "dela". As mulheres, geralmente, estão mais dispostas do que os homens para admitirem os problemas e avaliarem seus relacionamentos como problemáticos, manifestando, por vezes, o desejo de se separarem, enquanto que os homens desejam manter seu casamento (Carter \& McGoldrick, 2001; Féres-Carneiro, 2003; FéresCarneiro, 1995). Em pesquisa de dissertação de mestrado, Magalhães (1993, citado por Féres-Carneiro, 1998), através de entrevistas com 20 casais da classe média carioca, com idades variando de 25 a 55 anos, verificou que todas as mulheres, menos uma, definiram casamento como "relação amorosa". Enquanto todos os homens do grupo definiram casamento como "constituição de família".

Outra pesquisa, também brasileira, apontou que para as mulheres, quando a relação conjugal não vai bem, sobretudo no que se refere à admiração, à intimidade e ao relacionamento sexual, a separação conjugal parece inevitável (Féres-Carneiro, 1998). Em parte, a demanda de separação conjugal apresenta-se como predominantemente feminina, tal aspecto também pode ser ilustrado pela fala de Kate e de Ben: Não é o momento em que um de nós diz: “ isto é ridículo! Nós nos amamos. Todos os casais passam por isso. Vamos tentar de novo?" (Ben). De acordo com Féres-Carneiro (1998), isso se deve ao fato de que casamento é percebido de diferente maneira para o homem e para a mulher, conforme já mencionado.

Outro aspecto frequente que pode ser observado na relação de casal é a dificuldade de expressão de afetos e de sentimentos. Em uma pesquisa realizada, através de entrevistas semiestruturadas com vinte mulheres casadas, da cidade de Vitória (ES), Garcia e Tassara (2003) verificaram que os problemas mais frequentes mencionados pelas mulheres foram: a falta de diálogo, o temperamento difícil do parceiro e as divergências na educação dos filhos. No filme, Kate revela que a falta de diálogo e o silêncio acabam fazendo parte da relação quando a comunicação já está prejudicada: $O s$ piores silêncios são aqueles cheios com tudo que foi dito, dito errado, dito 300 vezes... Até que a briga vira a condição, não a exceção. E de repente torna-se a 
linguagem da relação (Katie). Estes dados de pesquisa corroboram a literatura que aponta a expressão das emoções como sendo um dos aspectos vitais na relação de casal (Walsh, 2002). A presença da expressão das emoções diferencia o casal saudável do disfuncional, constituindo-se em um dos aspectos vitais da comunicação a dois (Walsh, 2002). Para a autora, os casais saudáveis apresentam um processo ativo de definições de tarefas e de negociações, com regras de colaboração às diferenças e às semelhanças entre os parceiros e fronteiras bem definidas. Nesses casais, há um cuidado com a renegociação das regras implícitas e clareza na comunicação e na expressão de sentimentos. Em contraposição, os casais disfuncionais apresentam problemas na comunicação e na expressão de sentimentos adequados, bem como na simetria dos papéis e funções, além de apresentar pouca capacidade para lidar com as diferenças. A expressão dos sentimentos de amor, afeto e cuidado, de acordo com a autora, estaria também relacionada ao gênero e aos modelos internos de comunicação das emoções.

Outro aspecto que pode influenciar a relação conjugal é a percepção idealizada de seus parceiros e de seus relacionamentos. Alguns estudos apontam que quanto mais idealizada e positiva as percepções, mais intensa é a satisfação sobre o relacionamento conjugal (Fletcher, Simpson, Thomas \& Giles, 1999; Gottman, 1998). Há também pesquisas que mencionam que as mulheres consideram o afastamento do modelo idealizado de casamento como um problema na relação conjugal (Garcia \& Tassara, 2003). Contudo, corre-se o risco de que a idealização transforme-se em fantasia (Valle \& Osório, 2004). Para algumas pessoas, o casamento pode ser vivido como se estivessem no reino da fantasia, isso pode ser observado através da fala de Ben, que acreditava que viveria junto com Katie para sempre: Pensei que as coisas fossem assim, entre eu e Katie, que ficaríamos juntos para sempre (Ben). A fantasia do amor ideal, da pessoa perfeita que se encaixa a você sem nenhuma tensão, sem a necessidade de negociações e ajustes, aparece como uma forma de viverem juntos e de estabelecerem uma relação imersa na ilusão da pessoa perfeita e do ideal de "felizes para sempre" (Valle \& Osório, 2004; Norgen et al., 2004).

À medida que as expectativas de cada um dos cônjuges deixam de ser cumpridas, instala-se um clima de desavenças e de conflito, gerando mágoas: Há mágoas que a gente nunca supera. E achamos que o tempo diminuirá sua presença e, até certo ponto, diminui, mas ainda dói, porque... a mágoa dói (Katie). Um grupo de pesquisadores brasileiros constatou que os cônjuges se divorciam não porque desqualificam o casamento, mas porque o valorizam tanto que não aceitam que a relação conjugal não corresponda as suas expectativas (Féres-Carneiro, 2003; Féres-Carneiro \& Magalhães, 2000). Essa valorização pode ser ilustrada pela fala de Katie, a qual parece se dar conta de que a sua relação era permeada de expectativas e de significados: Fico me perguntando em que momento do casamento, uma colher torna-se apenas uma colher? (Katie).

Outra dificuldade presente no relacionamento entre duas pessoas é o estabelecimento de relações problemáticas com as famílias de origem do cônjuge. A família de origem pode exercer direta ou indiretamente um papel relevante nesse momento do ciclo evolutivo vital (Falcke, Wagner \& Mosmann, 2005). O casamento não envolve apenas a pessoa escolhida, mas todo o grupo de pessoas que constitui a sua rede social, havendo a modificação de sistemas inteiros e a criação de um terceiro (McGoldrick, 2001; Valle \& Osório, 2004). Katie você se tornou igual a tua mãe, tudo tem horário, tudo tem lugar. Nada pode ser espontâneo! (Ben); Lembra quando aquele psicanalista freudiano disse que quando duas pessoas vão pra cama, na verdade estão levando seis pessoas, o casal e os seus pais. Ninguém disse que seria fácil! (Katie). As experiências vividas nas famílias de origem estão diretamente associadas ao ajustamento conjugal e à maturidade experienciada na vida adulta, uma vez que são transmissoras de sistemas de crenças e de mitos, e de modelos parentais (Feng et al., 1999; Falcke, Wagner \& Mosmann, 2005).

Muitas vezes, ocorre de a relação conjugal mascarar inseguranças afetivas preexistentes na própria família de origem (Walsh, 2002). Outras vezes, os problemas refletem a incapacidade de o casal modificar o status familiar, normalmente identificados por fronteiras deficientes em torno do subsistema conjugal (McGoldrick, 2001). Nesses casos, os parentes podem ser intrusivos demais e o casal pode ter receio de colocar os limites ou pode ter dificuldades em estabelecer conexões adequadas com as famílias de origem, separando-se em um subsistema conjugal (Carter \& McGoldrick, 2001). Para essas autoras, os problemas conjugais podem estar relacionados a tensões específicas da relação conjugal, podendo ser deslocadas para um membro da família de origem. McGoldrick (2001) 
afirma que é mais fácil deslocar a tensão do que enfrentar e admitir que o próprio cônjuge tenha dificuldades em manejar os conflitos da relação. Compreender as experiências do passado do cônjuge e ampliar as possibilidades de construção de relacionamentos íntimos satisfatórios constitui um dos desafios de uma relação a dois (Falcke et al., 2005).

Assim, parece não existir um fator predominante que defina a qualidade e a satisfação da relação conjugal, mas um conjunto de fatores. As características da personalidade dos cônjuges, o tipo de relacionamento que eles construíram, valores, atitudes e momento do ciclo de vida familiar, presença de filhos, nível de escolaridade, socioeconômico e cultural, trabalho remunerado, e experiência sexual anterior ao casamento, expectativas sobre o parceiro, bem como as vivências da infância e as influências de suas famílias de origem parecem ser fatores que interferem na relação conjugal (Dessen \& Junior, 2005; Falcke et al., 2005; Sardinha, Falcone \& Ferreira, 2009). A esse respeito, a amiga de Katie refere que a satisfação no casamento estaria relacionada à aceitação da diferença de gênero: $A$ chave do casamento feliz é aceitar o abismo que existe entre homens e mulheres (amiga de Katie).

A satisfação na relação conjugal está associada, entre outros aspectos, à aceitação das diferenças e do reconhecimento de que essas podem, não apenas afastar o casal, mas também os aproximar e enriquecer a experiência compartilhada (Valle \& Osório, 2004). A relação conjugal também pode se transformar em fonte de crescimento e de desenvolvimento pessoal, além de aprendizagem, se houver espaço para as trocas e diferenças pessoais (Minuchin, 1990). A funcionalidade de uma relação de casal estaria relacionada ao equilíbrio entre manutenção de uma estrutura estável e flexibilidade e tolerância nos papéis e nas eventuais crises, uma vez que as coalizões são inteiramente saudáveis (Andolfi, 1995; Walsh, 2002).

Dessa forma, o próprio casal seria o responsável pelo destino de sua relação, já que teria que fazer suas próprias descobertas e escolhas, buscando alcançar um relacionamento satisfatório, uma alquimia íntima, uma relação simétrica (Valle \& Osório, 2004; Walsh, 2002). Se cada um dos cônjuges se comprometer com sua escolha e acreditar no que está fazendo, a relação conjugal pode ser uma opção viável de relacionamento que corresponda às expectativas de cada um dos parceiros (Norgren et al., 2004). De acordo com Valle e Osório (2004), quando ambos os cônjuges olham na mesma direção geralmente encontram maneiras de ajudar-se mutuamente na resolução dos objetivos, sejam estes individuais ou de ordem conjugal. Esse aspecto pode ser ilustrado pela fala de Ben, que percebe a potencialidade do casal para lidar com as desavenças, quando estivessem em zona desmilitarizada, sem ameaça:

Sempre achei que, apesar do que nós passássemos, mesmo sendo doloroso, se nossos pés se encontrassem sob os cobertores, mesmo com um leve toque, saberíamos que estávamos em zona desmilitarizada, que ficaríamos bem, que ainda éramos "nós". (Ben)

A esse respeito, Walsh (2002) também menciona que o equilíbrio entre proximidade e respeito ao distanciamento e às diferenças individuais pode ser reflexo da coesão do casal, que se torna essencial para a relação, visto que protege a integridade do casal e previne a intrusão e a ruptura do vínculo.

Tanto na família quanto no relacionamento conjugal são necessárias estabilidade e habilidade para mudanças, em um jogo contínuo de complementaridade (Olson, 2000). O modo psicológico de ser de cada parceiro - a combinação de temperamento, personalidade, caráter e história pessoal - exerce uma influência no outro, que o leva a participar de "roteiros já conhecidos", induzindo aos papéis já designados, modelos de comportamento e de comunicação (Bernstein, 2002). Essa complementariedade, muitas vezes, constitui-se em um dos maiores desafios da vida a dois. A relação conjugal é construída, de acordo com Zordan et al. (2005), a partir do amor, mais desejo, mais investimento, mais comprometimento em construir uma vida a dois, superando as crises e cumprindo com as tarefas inerentes ao ciclo vital. Tal aspecto pode ser observado no filme, visto que os personagens se dão conta de que uma história de amor entre duas pessoas deve ser ancorada pela cumplicidade, pelo conhecimento mútuo, pelo respeito às individualidades, dentre outros aspectos:

Há uma história aqui e histórias não são construídas do dia para a noite. Eu gosto desta história, sei como você está quando acorda de manhã, só olhando sua sobrancelha. Essa dança se aperfeiçoa com o tempo. E é mais difícil do que eu pensei que fosse, mas há mais coisas boas do que coisas ruins na nossa relação. E não devemos desistir... Vamos admitir todos temos características irritantes. Mas, eu adoro o teu jeito... Eu te amo, eu amo a história de nós dois. (Katie) 


\section{CONSIDERAÇÕES FINAIS}

$\mathrm{O}$ tema da conjugalidade permeia tanto a prática clínica com casais quanto a pesquisa, visto que a formação da conjugalidade contempla a inclusão de dois desejos, dois sujeitos, duas histórias que devem "dançar", conforme o seu ritmo, e se aperfeiçoar com o tempo (Whitaker, 1990). Uma relação que se constrói prisioneira de crenças e valores impede a criatividade e a construção de matizes. Para que um relacionamento seja satisfatório é preciso investir constantemente na relação, empenhando-se para que ele seja harmonioso para os dois, tentando encontrar equilíbrio entre conjugalidade e individualidade, partilhando interesses e relacionamento afetivo-sexual, buscando um jogo contínuo de complementariedade. Casais satisfeitos parecem ser funcionais, quando mantêm laços emocionais fortes com seu cônjuge, alteram a estrutura de poder, papéis e regras do relacionamento ao longo do ciclo de vida conjugal.

A história de um casal está associada, entre outras, a duas histórias individuais, às histórias familiares, além de estar relacionada à própria história que os cônjuges constroem a partir de suas escolhas. Ainda que haja muitas divergências e discordâncias no relacionamento conjugal, é possível construir uma história de vida que contemple o amor e o desejo, de ambos os cônjuges. Estabelecer uma alquimia íntima própria capaz de enfrentar o difícil convívio da individualidade com a conjugalidade é o grande desafio para quem quer construir uma História de Nós Dois.

Tendo em vista que grande parte dos estudos centra-se nos diferentes aspectos da conjugalidade, havendo destaque para a qualidade e a satisfação na relação e também de sua dissolução através do processo de separação (Féres-Carneiro, 2003; Sardinha et al., 2009), essa discussão convida a uma reflexão para a prática da terapia com casais em crise. Nesse sentido, o presente artigo, oriundo de um trabalho do primeiro ano do curso de especialização em Terapia Individual, Familiar e de Casal, do Instituto da Família de Porto Alegre, buscou estimular a discussão a respeito da heterogeneidade das questões que envolvem e influenciam as dimensões individualidade e conjugalidade em casais em crise, ilustradas através de um filme. $\mathrm{Na}$ medida em que os casais entram em contato com os aspectos e as demandas envolvidas na relação a dois tornam-se corresponsáveis por suas ações. Esta tomada de consciência teria valor terapêutico, pois os auxi- liaria no enfrentamento de situações difíceis, facilitando uma convivência conjugal mais satisfatória e harmônica.

\section{REFERÊNCIAS}

Andolfi, M. (1995). Crise do casal e família transgeracional. In M. Andolfi, C. Angelo, \& C. Saccu (Eds.), O casal em crise (pp. 105-119). São Paulo: Summus.

Ariés, P. (1981). História social da criança e da família (D. Flaksman, Trans.) Rio de Janeiro: Livros Técnicos e Científicos.

Bernstein, A. C. (2002). Recasamento: Redesenhando o casamento. In P. Papp (Ed.), Casais em perigo: Novas diretrizes para terapeutas (pp. 295-323). (D. A. E. Burguño, Trans.) Porto Alegre: Artmed.

Carter, B., \& McGoldrick, M. (2001). As mudanças no ciclo de vida familiar: Uma estrutura para a terapia familiar. Porto Alegre: Artes Médicas.

Dessen, M. A., \& Junior, A. L. (2005). A ciência do desenvolvimento humano: Tendências atuais e perspectivas futuras. Porto Alegre: Artes Médicas.

Falcke, D., Diehl, J. A., \& Wagner, A. (2002). Satisfação conjugal na atualidade. In A. Wagner (Org.), Família em cena: Tramas, dramas e transformações (pp. 172-188). Petrópolis: Vozes.

Feng et al. (1999). Intergeracional transmission of marital quality and marital instability. Journal of Marriage and Family, 61, 451-463.

Féres-Carneiro, T. (1995). Casais em terapia: Um estudo sobre a manutenção e a ruptura do casamento. Jornal Brasileiro de Psiquiatria, 44, 67-70.

Féres-Carneiro, T. (1998). Casamento contemporâneo: O difícil convívio da individualidade com a conjugalidade. Psicologia: Reflexão e Crítica, 11, 379-394.

Féres-Carneiro, T. (2003). Separação: O doloroso processo de dissolução da conjugalidade. Estudos de Psicologia (Natal), 8, 367-374.

Féres-Carneiro, T, \& Diniz-Neto, O. (2010). Construção e dissolução da conjugalidade: Padrões relacionais. Paidéia, 20, 269278.

Féres-Carneiro, T., \& Magalhães, A. S. (2000). Retorno da conjugalidade sobre a subjetividade dos parceiros: Uma questão para a clínica psicanalítica do casal. Retirado de http:// egp.dreamhosters.com/EGP/141-retorno.shtml

Fletcher, G. J. O., Simpson, J. A., Thomas, G., \& Giles, L. (1999). Ideals in intimate relationships. Journal of Personality and Social Psychology, 76, 72-89.

Garcia, M. L. T., \& Tassara, E. T. O. (2003). Problemas no casamento: Uma análise qualitativa. Estudos de Psicologia (Natal), $8,127-133$.

Gottman, J. M. \& Levenson, R. W. (1992). Marital processes predictive of later dissolution: Behavior, physiology and health. Journal of Personality and Social Psychology, 63, 221233.

Gottman, J. M. (1993). The roles of conflict engagement, escalation and avoidance in marital interaction: A longitudinal view 
of five types of couples. Journal of Consulting and Clinical Psychology, 49, 169-197.

Gottman, J. M. (1998). Psychology and the study of marital processes. Annual Review of Psychology, 49, 169-197.

Levandowski, D., Piccinini, C. A., \& Lopes, R. C. S. (2009). Individualidade e conjugalidade na relação de casal de adolescentes. Psicologia em Estudo, 14, 679-687.

Magalhães, A. S., \& Féres-Carneiro, T. (2003). Conjugalidade e subjetividades contemporâneas: O parceiro como instrumento de legitimação do "eu". Trabalho apresentado no Segundo Encontro Mundial dos Estados Gerais da Psicanálise, Rio de Janeiro. Retirado de http://egp.dreamhosters.com/encontros/ mundial_rj/download/5a_Carneiro_39020903_port.pdf

McGoldrick, M. (2001). A união das famílias através do casamento: O novo casal. In B. Carter \& M. McGoldrick (2001), As mudanças no ciclo de vida familiar: Uma estrutura para a terapia familiar (pp. 184-205). Porto Alegre: Artes Médicas.

Minuchin, S. (1990). Famílias: Funcionamento e tratamento (J. A. Cunha, Trad.). Porto Alegre: Artes Médicas.

Minuchin, S., \& Fishman, H. C. (1990). Técnicas de terapia familiar (C. Kinsch e M. E. F. R. Maia, Trads.). Porto Alegre: Artes Médicas.

Mosmann, C. P., Wagner, A., \& Féres-Carneiro, T. (2006). Qualidade conjugal: Mapeando conceitos. Paidéia, 35, 315-325.

Norgren, M. B., Souza, R. M., Kaslow, F., Hammerschmidt, H., \& Sharlin, S. (2004). Satisfação conjugal em casamentos de longa duração: Uma construção possível. Estudos de Psicologia ( $\mathrm{Na}$ tal), 9, 575-584.

Olson, D. H. (2000). Circumplex model of marital and family systems. Journal of Family Therapy, 22, 144-167.
Sardinha, A., Falcone, E. M., \& Ferreira, M. C. (2009) As relações entre a satisfação conjugal e as habilidades sociais percebidas no cônjuge. Psicologia: Teoria e Pesquisa, 25, 395-402.

Singly, F. (1988). Un drôle de je: Le moi conjugal. Dialogue, 102, 3-5.

Valle, M. E., \& Osório, L. C. (2004). Alquimia íntima: A nova química do casal. Porto Alegre: Literalis.

Walsh, F. (2002). Casais saudáveis e casais disfuncionais: Qual a diferença? In M. Andolfi (Ed.), A crise do casal: Uma perspectiva sistêmico-relacional (pp.13-28). Porto Alegre: Artmed.

Whitaker, A. (1990). Dançando com a família. Porto Alegre: Artes Médicas.

Whitaker, C. (1995). As funções do casal. In M. Andolfi, C. Angelo \& C. Saccu (Eds.), O casal em crise (pp. 21-28). São Paulo: Summus.

Willi, J. (1975). La pareja humana: Relación y conflicto. Madrid: Morata.

Willi, J. (1995). A construção didática da realidade. In M. Andolfi, C. Angelo \& C. Saccu (Eds.), O casal em crise (pp. 15-27). São Paulo: Summus.

Zordan, E. P., Falcke, D., \& Wagner, A. (2005) Copiar ou (re)criar? Perspectivas histórico-contextuais do casamento. In A. Wagner (Org.), Como se perpetua a família? A transmissão dos modelos familiares (pp. 47-65). Porto Alegre: Edipucrs. 
